\title{
Evaluating a Conditional Cash Transfer Scheme in a Maternal Health Care Utilization Program Among Rural Pregnant Women in Mysore District, India
}

\author{
Sandra Kiplagat, ${ }^{1, *}$ Makella S. Coudray, ${ }^{1}$ Kavitha Ravi, ${ }^{2}$ Poornima Jayakrishna, ${ }^{2}$ Karl Krupp, ${ }^{2,3}$
} Anjali Arun, ${ }^{2}$ and Purnima Madhivanan ${ }^{2-5}$

\begin{abstract}
Background: According to the World Bank report in 2015, the maternal death rate in India was 174 per 100,000, which is among the highest in the world. The Indian Government launched the Janani Suraksha Yojana (JSY) conditional cash transfer program in 2005 to curb the adverse birth outcomes by promoting institutional delivery and providing antenatal care (ANC) services for pregnant women. This study evaluates the factors associated with JSY conditional cash transfer program in rural Mysore, India.

Methods: Between 2011 and 2014, a prospective cohort study was conducted to examine the feasibility and acceptability of integrated ANC and HIV testing using mobile clinics in rural Mysore. Pregnant women in the Mysore Taluk provided an informed consent and answered an interviewer-administered questionnaire in local language, Kannada. All women underwent routine ANC services and were followed-up immediately after delivery, and 6 months and 12 months after delivery. Binary logistic regression was performed to identify factors associated with JSY benefits.

Results: The mean age of the 1,806 mothers was $21.2 \pm 2.2$ years and $58.9 \%$ of the mothers had primary education. Nearly half (51.6\%) of the women reported having received JSY benefits. Factors associated with receiving JSY benefits included pregnant woman's partner not having any formal education (adjusted odds ratio [AOR]: 1.35; 95\% confidence interval [Cl]: 1.01-1.80), having income $\leq 4,000$ Indian Rupees (AOR: 1.47; 95\% Cl: $1.04-$ 2.09), rare visits (once in 3 months visit) with Accredited Social Health Activists (AOR: 3.55; 95\% Cl: 1.55-8.51), and delivery in a public institution (AOR: 1.23; 95\% Cl: 1.01-1.51).

Conclusions: While JSY has been operational in India since 2005, there continue to remain major gaps in the receipt of JSY services in rural India. Future interventions should include targeted services and expansion of JSY scheme, specifically among rural pregnant women, who are most at need of these services.
\end{abstract}

Keywords: conditional cash transfer; India; Janani Suraksha Yojana; pregnant; rural

\section{Introduction}

Maternal health care access remains a significant public health challenge in India. According to the World Bank report in 2015, the maternal death rate was 174 per 100,000 (Ref. ${ }^{1}$ ). Majority of these deaths have been attributed to poor in-facility birth coverage, unskilled birth attendance, and inaccessibility to quality obstetric care. ${ }^{2,3}$ The Indian Government launched the Janani Suraksha Yojana (JSY-translated as the Safe Motherhood Scheme) conditional cash transfer

\footnotetext{
${ }^{1}$ Department of Epidemiology, Robert Stempel College of Public Health and Social Work, Florida International University, Miami, Florida, USA.

${ }^{2}$ Public Health Research Institute, Yadavgiri, Mysore, India.

${ }^{3}$ Department of Health Promotion Sciences, Mel and Enid Zuckerman College of Public Health, University of Arizona, Tucson, Arizona, USA.

${ }^{4}$ Division of Infectious Diseases, College of Medicine, University of Arizona, Tucson, Arizona, USA.

${ }^{5}$ Department of Family and Community Medicine, College of Medicine, University of Arizona, Tucson, Arizona, USA.
}

*Address correspondence to: Sandra Kiplagat, MSc, PhDc, Department of Epidemiology, Robert Stempel College of Public Health and Social Work, Florida International University, 11200 SW 8th Street, 4th Floor, Miami, FL 33199, USA, E-mail: skipl001@fiu.edu 
program in 2005 to curb adverse birth outcomes by promoting institutional delivery and providing antenatal services. ${ }^{3,4}$ JSY is a component of the National Rural Health Mission that aimed to provide cash assistance and minimize out-of-pocket expenditure of maternity care, including antenatal care (ANC), delivery, and postnatal care. ${ }^{4,5}$

JSY promotes ANC visits and institutional delivery by frontline health workers commonly referred to as accredited social health activists (ASHA). ${ }^{4,6}$ They provide ancillary services, including transportation, navigation of the health system, and referral services. ${ }^{6,7}$ The cash benefits vary based on lowperforming and high-performing states established on the number of institutional deliveries before the implementation of JSY. Low-performing states had been characterized as poor in-facility birth coverage and health services, and financial assistance is provided to all women regardless of their socioeconomic status or caste, whereas high-performing states had a history of higher rates of institutional deliveries and improved health services. ${ }^{8,9}$

According to the Ministry of Health and Welfare, the government would provide 1,400 Indian Rupees (INR) (approximately U.S. Dollar [USD] 20.12) to women belonging in rural and 1,000 INR (approximately USD 14.37) in urban low-performing states, whereas those in high-performing states would receive 700 INR and 600 INR for rural and urban areas, respectively. ${ }^{9,10}$ In high-performing states, financial assistance is provided to only women issued with the below poverty line (BPL) card, and those who belonged to a scheduled caste or tribe, ${ }^{6}$ whereas cash payments are given to all women in low-performing states.

Since its inception more than a decade ago, it remains the largest conditional cash transfer program in the world serving up to 10 million pregnant women each year and has a budget of approximately USD 452 million. ${ }^{4,9,11}$ Although this program was established more than a decade ago, prior studies have reported lack of awareness among Indian pregnant women. ${ }^{12}$ Moreover, there have been inconsistencies observed by JSY benefits that have varied from state to state, but largely influenced by educational attainment, possession of BPL cards, and increased ANC. ${ }^{6,13}$ There have been very few studies that have explored the impact of JSY in rural communities. Majority of the studies have been large scale evaluating low-performing compared with high-performing states. $^{4,6,10,13}$
Since JSY has been operational for $>14$ years in the state of Karnataka, it was found appropriate to evaluate how JSY performed in the Mysore Subdistrict. The government assigned Karnataka as a high-performing state with mothers residing in rural areas receiving 700 INR and mothers residing in urban areas receiving 600 INR. This would be among the first studies conducted in Mysore District. The aim of the study was to assess how JSY performed in rural Mysore, specifically examining the receipt of JSY benefits, utilization, and factors associated with JSY benefits.

\section{Methods}

Study setting

Based on the 2011 census, the Mysore District had a population of $3,001,027$, of which $1,489,527$ were females. ${ }^{14}$ Of the population, $58.5 \%$ resided in rural villages. The literacy rate among females $(67.1 \%)$ was lower compared with males (78.5\%). ${ }^{14}$ Approximately $87.7 \%$ of the Mysore population self-identified as Hindu, $9.7 \%$ as Muslim, and $1.3 \%$ as others. ${ }^{14}$ Scheduled caste comprised $17.9 \%$, while scheduled tribe was $11 \%$ of the population. The languages commonly spoken in Mysore were Kannada (81.2\%), Urdu (8.6\%), and Telugu (3.3\%). The labor workforce was mainly agricultural sector and the average per capita income was 95,591 INR equivalent to 1,374 USD. $^{14}$ More specifically, the National Family Health Survey4 indicated that only $31.4 \%$ of rural pregnant women in Karnataka received full ANC, which comprised four ANC visits, at least one tetanus toxoid injection, and daily iron folic acid tablets for 100 or more days. ${ }^{15}$ The maternal mortality ratio (MMR) in Karnataka remains the highest in South India without significant improvements comparing 2011-2013 and 2014-2016 years with MMR as 133 and 108 per 100,000 live births, respectively. ${ }^{1}$

\section{Study design}

Between 2011 and 2014, a prospective cohort study, known as the Saving Children Improving Lives (SCIL) project was initiated in the rural Mysore Subdistrict, Karnataka. The SCIL project utilized mobile clinics to deliver integrated ANC and HIV testing with the support of community health workers. This study is a health care utilization analysis conducted from the SCIL project. Detailed methods for the SCIL project were described elsewhere by Kojima et al. ${ }^{16}$ 


\section{Compliance with ethical standards}

Ethical approval and consent to participate. The protocol of the study was reviewed and approved by the Institutional Review Boards of Public Health Research Institute of India and Florida International University. Confidentiality of all participants was maintained using a study identification number on all study records. Permissions were obtained from the District AIDS Prevention and Control Officer, the District Health Officer, and the Taluk Medical Officer for Mysore District, before carrying out the study.

\section{Study participants}

A total of 1,820 pregnant women living in Mysore District, received integrated ANC and HIV testing through the SCIL project. During the mobile clinic visit, interested pregnant women receiving clinical services were informed of the study and invited to participate in the study. Eligible participants were pregnant women, 18 years and older residing in select village for $>6$ months. If women met the eligibility criteria, they underwent an informed consent process in a private location. On completion of the informed consent process, participants completed an interviewer-administered questionnaire in the local language of Kannada. This comprised sociodemographic, current reproductive history, and clinical laboratory examinations for sexuallytransmitted infections during pregnancy. The questionnaire comprised maternal and newborn infant health complications, birth outcomes, as well as utilization of health services after childbirth. All women enrolled in the study were followed-up immediately after delivery, and 6 and 12 months postdelivery.

\section{Outcome and explanatory variable selection}

The main outcome of this regression analysis assessed the factors that influenced the receipt of JSY benefits reported as "yes" or "no" during and after pregnancy. The explanatory variables included education defined as "none" for no formal education, "primary" as 1-8 years of education, and "secondary" for those with 8 or more years of education. According to India's Ministry of Statistics and Programme Implementation, the monthly per capita income in India is $\sim 10,000 \mathrm{INR}^{17}$ With regard to total monthly household income, majority of the participants mainly relied on subsistence farming and so it was defined as low at $\leq 4,000$ INR (approximately USD 57.9 with $1 \mathrm{USD}=69 \mathrm{INR}$ during the period of data collection), middle as 4,000-10,000 INR (USD 144.90), and high as $\geq 10,000$ INR. Since, the monthly per capita income was stratified into the respective categories, the cutoff for the poverty line was established as $\leq 4,000$ INR. Belonging to a microeconomic group was labeled as "yes" or "no."

The social support program and services offered to pregnant women by the government, including ASHA and auxiliary nurse midwives (ANM), was also assessed. The frequency of the ASHA visits during pregnancy and for ANC visits included regular visits (once a month), occasional visits (twice a month), rare visits (once in 3 months), and never (no visits at all). Moreover, ASHA's role to plan transport arrangements before delivery was assigned as yes or no. Low birth weight of the infant was defined as having birth weight $<2,500 \mathrm{~g}$ at the time of delivery.

Vital status of the baby was defined as "living" or "dead" within 28 days of delivery. Place of childbirth was categorized as "home," "public institution," which included subcenter, primary health center, or district health hospital, and "private institution" as maternity or private nursing home. ANC visits have been defined as " $\leq 4$ ANC visits," "5-9 ANC visits," and "greater than 9 ANC visits." Birth attendance was defined as individuals present during the delivery process and this was "traditional birth attendant," "relative," "auxiliary nurse midwife," and "doctor/nurse." All sociodemographic variables were self-reported by the study participants at baseline, and during follow-up. The pregnancy outcomes were assessed during follow-up and confirmed by the hospital discharge notes.

\section{Statistical analyses}

Data were entered in a Microsoft Access database and then exported to Excel database to allow for data analysis (Microsoft Corporation, Redmond, WA). Normality tests and nonparametric tests were conducted for those variables that violated normal distribution assumptions. Descriptive analyses were conducted for both categorical and continuous variables. Frequencies and percentages were done for categorical variables, while mean and standard deviation were calculated for continuous variables. Chi-square analyses and analysis of variance were computed to identify any significant associations in the categorical and continuous variables conducted after normality tests. Variables with chi-squared tests with $p$-values $\leq 0.25$ were included in the binary logistic regression. Binary logistic regression was performed to identify factors influencing receipt of JSY benefits and the explanatory variables. The measures of association included crude 
and adjusted odds ratio (AOR), and the associated 95\% confidence intervals (CIs). The variables were selected a priori for the model based on previous literature. ${ }^{12,18}$ A two-tailed statistical significance test of $p \leq 0.05$ was done for all the analyses. All analyses were performed using Statistical Package for the Social Sciences (SPSS) version 23 (SPSS, Inc., Chicago, IL).

\section{Results}

\section{Demographic characteristics}

Of the 1,820 women enrolled in the study, a total of 1,806 women were eligible for this analysis. Fourteen women $(0.7 \%)$ were excluded due to incomplete data on the survey. The mean age of the mothers was $21.2 \pm 2.2$ years. The majority of the women had more than primary education $(58.9 \%$ and $46.0 \%$ for the women and their spouses, respectively). The primary religion reported was Hindu (98.6\%). More than a third (36.4\%) earned $\leq 4,000$ INR (approximately USD 56) monthly, and almost half belonged to a microeconomic self-help group (49.6\%). Just over half of the women $(56.2 \%)$ delivered at a maternity or private nursing institution, while the rest $42 \%$ delivered in a subcenter or primary health care facility or district hospital. Only $1.3 \%$ of the women delivered at home. The most common mode of delivery was vaginal $(82.0 \%)$ and $60 \%$ of the women were primigravida. Births were commonly assisted by a doctor or nurse (86.0\%) followed by ANM (12.0\%). Nearly $13.5 \%$ of the women gave birth to low birth weight infants $(<2,500 \mathrm{~g})$.

\section{JSY beneficiaries}

Nearly 50\% (51.6\%) of the women reported having received JSY benefits (Table 1). Approximately 52.1\% and 38.9\% had received JSY from ANM and ASHA, respectively (Table 2 ). Nearly $45.5 \%$ received 1,500 INR, while $15 \%$ received 1,000 INR, $37.7 \%$ received $700 \mathrm{INR}$, and $1.7 \%$ received 500 INR. Majority of them $(64.9 \%)$ received the JSY benefits within 30 days of delivery.

Table 1 shows bivariate analysis of JSY beneficiaries. Among those who received JSY, 59.9\% had more than primary education, while $37.7 \%$ had a total monthly income of $\leq 4,000$ INR. More than $50 \%$ (53.0\%) of those who received JSY had an annual income of 4,000 10,000 INR. On the contrary, $35 \%$ of those who earned $\leq 4,000$ INR did not receive any JSY benefits. Of those who earned $\leq 4,000$ INR, nearly half $(46.6 \%)$ did not receive any JSY benefits. Approximately $13.5 \%$ of the participants who received JSY reported never having had
Table 1. Sociodemographic Characteristics of Pregnant Women Attending Saving Children Improving Lives Mobile Clinics, in Rural Mysore, India $(N=1,806)$

\begin{tabular}{|c|c|c|c|}
\hline \multirow[b]{2}{*}{ Variables } & \multicolumn{2}{|c|}{ Receipt of JSY benefits } & \multirow[b]{2}{*}{$p$} \\
\hline & $\begin{array}{c}\text { No }(n=874 ; \\
48.4 \%) \\
n(\%)\end{array}$ & $\begin{array}{c}\text { Yes } \\
(n=932 ; \\
51.6 \%) \\
n(\%)\end{array}$ & \\
\hline \multicolumn{4}{|l|}{ Sociodemographic factors } \\
\hline Age (mean, SD) in years & $21.4 \pm 3.2$ & $21.1 \pm 3.1$ & 0.044 \\
\hline $\begin{array}{l}\text { Pregnant woman's education } \\
\text { (in years) }\end{array}$ & & & 0.219 \\
\hline No education & $64(7.3)$ & $50(5.4)$ & \\
\hline Primary $(1-8)$ & $304(34.8)$ & $324(34.8)$ & \\
\hline More than primary $(>8)$ & $506(57.9)$ & $558(59.9)$ & \\
\hline Partner's education (in years) & & & 0.038 \\
\hline No education & $149(17.0)$ & $172(18.5)$ & \\
\hline Primary (1-8) & 296 (33.9) & $358(38.4)$ & \\
\hline More than primary $(>8)$ & $429(49.1)$ & $402(43.1)$ & \\
\hline Religion & & & 0.968 \\
\hline Hindu & $862(98.6)$ & 919 (98.6) & \\
\hline Muslim/others & $12(1.4)$ & $13(1.4)$ & \\
\hline $\begin{array}{l}\text { Total monthly household income } \\
\text { (in INR) }\end{array}$ & & & 0.141 \\
\hline$\leq 4,000$ & $306(35.0)$ & $351(37.7)$ & \\
\hline $4,001-10,000$ & $463(53.0)$ & $494(53.0)$ & \\
\hline$>10,000$ & $105(12.0)$ & $87(9.3)$ & \\
\hline $\begin{array}{l}\text { Microeconomic self-help group } \\
\text { membership }\end{array}$ & & & 0.080 \\
\hline No & $459(52.5)$ & $451(48.4)$ & \\
\hline Yes & $415(47.5)$ & $481(51.6)$ & \\
\hline \multicolumn{4}{|l|}{ Programs } \\
\hline ASHA visits during pregnancy & & & $<0.001$ \\
\hline Regularly (once a month) & $638(73.0)$ & $722(77.5)$ & \\
\hline Occasionally (once in 2 months) & $73(8.4)$ & $51(5.5)$ & \\
\hline Rarely (once in 3 months) & $9(1.0)$ & $33(3.5)$ & \\
\hline Never & $154(17.6)$ & $126(13.5)$ & \\
\hline $\begin{array}{l}\text { ASHA accompanying woman to her } \\
\text { ANC visits }\end{array}$ & & & $<0.001$ \\
\hline Regularly (once a month) & $410(46.9)$ & $448(48.1)$ & \\
\hline Occasionally (once in 2 months) & $92(10.5)$ & $59(6.3)$ & \\
\hline Rarely (once in 3 months) & $11(1.3)$ & $37(4.0)$ & \\
\hline Never & $361(41.3)$ & $388(41.6)$ & \\
\hline $\begin{array}{l}\text { ASHA arranged for ambulance } \\
\text { during labor }\end{array}$ & & & $<0.001$ \\
\hline No & $507(58.0)$ & $419(45.0)$ & \\
\hline Yes & $367(42.0)$ & $513(55.0)$ & \\
\hline \multicolumn{4}{|l|}{ Pregnancy outcomes } \\
\hline Birthweight & & & 0.831 \\
\hline Low birth weight $(<2,500 \mathrm{~g})$ & $114(14.5)$ & $130(14.2)$ & \\
\hline Normal birth weight $(\geq 2,500 \mathrm{~g})$ & $670(88.5)$ & $787(85.8)$ & \\
\hline Vital status of the baby & & & $<0.001$ \\
\hline Died & $90(10.3)$ & $13(1.4)$ & \\
\hline Living & $784(89.7)$ & 919 (98.6) & \\
\hline Antenatal checkups & & & 0.021 \\
\hline$\leq 4$ antenatal checkups & $25(3.2)$ & $14(1.5)$ & \\
\hline 5-9 antenatal checkups & $664(84.6)$ & $813(88.5)$ & \\
\hline 10 and more antenatal visits & $96(12.2)$ & $92(10.0)$ & \\
\hline Delivery place & & & 0.015 \\
\hline Home & $15(1.9)$ & $7(0.8)$ & \\
\hline Public institution & $311(39.7)$ & $413(44.9)$ & \\
\hline Private institution & $458(58.4)$ & $499(54.3)$ & \\
\hline Birth attendance & & & 0.028 \\
\hline Traditional birth attendant & $4(0.5)$ & $7(0.8)$ & \\
\hline Relative & $10(1.3)$ & $2(0.2)$ & \\
\hline Auxillary nurse midwife & 89 (11.4) & $126(13.7)$ & \\
\hline Doctor/nurse & $681(86.9)$ & $784(85.3)$ & \\
\hline
\end{tabular}

Public institution: subcenter, primary health care, district health center. Private institution: maternity home/private nursing.

ANC, antenatal care; ASHA, accredited social health activists; INR, Indian Rupees; JSY, Janani Suraksha Yojana; SD, standard deviation. 
Table 2. Characteristics of Janani Suraksha Yojana Recipients Among Saving Children Improving Lives Program Participants in Rural Mysore, India

\begin{tabular}{lc}
\hline Variables & Frequency (\%) \\
\hline JSY benefits & \\
Receipt of JSY benefits & \\
No & $874(48.4)$ \\
Yes & $932(51.6)$ \\
From whom were provided JSY benefits & \\
ASHA & $363(38.9)$ \\
Anganwadi teacher & $65(7.0)$ \\
ANM & $486(52.1)$ \\
Doctor & $18(1.9)$ \\
Receipt of JSY benefits (in INR) & $17(1.8)$ \\
500 & $351(37.7)$ \\
700 & $140(15.0)$ \\
1,000 & $424(45.5)$ \\
1,500 & $210(22.5)$ \\
Time period for JSY benefit delivery & $103(11.1)$ \\
Within 7 days & $605(64.9)$ \\
Between 7 and 30 days & $14(1.5)$ \\
After 30 days & \\
After 1 year & $451(48.4)$ \\
Microeconomic self-help group membership & $481(51.6)$ \\
No &
\end{tabular}

ANM, auxiliary nurse midwives.

visits from an ASHA worker during the course of their pregnancy. The proportion of women having ASHA accompany them regularly (once a month) to their ANC visits was significantly higher among those who received JSY compared with those without JSY benefits. The women were also significantly less likely to have delivered at home if the woman had received JSY services compared with those who did not. Moreover, infant deaths among women who received JSY benefits (1.4\%) was significantly lower compared with those who did not receive JSY benefits (10.4\%).

\section{Factors associated with receipt of JSY benefits}

Of the 1,806 women, only 932 (51.6\%) (95\% CI: 49.353.9) reported having received JSY benefits. Results of logistic regression analyses are presented in Table 3. In the adjusted model, pregnant woman's spouse having no formal or primary education, having $\leq 4,000 \mathrm{INR}$ income, not receiving visits from ASHA, and delivery at a subcenter or primary health care center or district hospital were significant determinants of JSY receipt of services. Pregnant women's spouse without any formal education had 1.4 times increased odds of receiving JSY (AOR: 1.35; 95\% CI: 1.01-1.80) compared with those with more than primary education ( $>8$ years). Moreover, spouses who completed primary education (8 years) had 1.3 times increased odds of receiving
Table 3. Sociodemographic Factors, Program Initiatives, and Birth Outcomes by Receipt of Janani Suraksha Yojana Benefits

\begin{tabular}{|c|c|c|}
\hline \multirow[b]{2}{*}{ Variables } & \multicolumn{2}{|c|}{ Receipt of JSY benefits } \\
\hline & $\begin{array}{l}\text { Unadjusted OR } \\
\qquad(95 \% \mathrm{Cl})\end{array}$ & $\begin{array}{c}\text { AOR* }^{*} \\
(95 \% \mathrm{Cl})\end{array}$ \\
\hline \multicolumn{3}{|l|}{ Sociodemographic factors } \\
\hline Age (mean, SD) & $0.97(0.94-0.99)$ & $0.98(0.94-1.01)$ \\
\hline \multicolumn{3}{|l|}{$\begin{array}{l}\text { Pregnant woman's education } \\
\quad \text { (in years) }\end{array}$} \\
\hline No education & $0.71(0.48-1.05)$ & $0.71(0.46-1.09)$ \\
\hline Primary (1-8) & $0.97(0.79-1.18)$ & $0.90(0.73-1.12)$ \\
\hline More than primary $(>8)$ & Ref. & Ref. \\
\hline \multicolumn{3}{|l|}{ Partner's education (in years) } \\
\hline No education & $1.23(0.95-1.60)$ & 1.35 (1.01-1.80) \\
\hline Primary (1-8) & $1.29(1.05-1.59)$ & 1.31 (1.05-1.64) \\
\hline More than primary $(>8)$ & Ref. & Ref. \\
\hline \multicolumn{3}{|l|}{$\begin{array}{l}\text { Total monthly household } \\
\text { income (in INR) }\end{array}$} \\
\hline$\leq 4,000$ & $1.38(1.00-1.91)$ & 1.47 (1.04-2.09) \\
\hline $4,001-10,000$ & $1.29(0.94-1.76)$ & 1.40 (1.01-1.95) \\
\hline$>10,000$ & Ref. & Ref. \\
\hline \multicolumn{3}{|l|}{$\begin{array}{l}\text { Microeconomic self-help group } \\
\text { membership }\end{array}$} \\
\hline No & $0.85(0.71-1.02)$ & $0.82(0.68-1.01)$ \\
\hline Yes & Ref. & Ref. \\
\hline \multicolumn{3}{|l|}{ Programs } \\
\hline \multicolumn{3}{|l|}{ ASHA visits during pregnancy } \\
\hline Regularly (once a month) & 1.38 (1.07-1.79) & $1.21(0.89-1.67)$ \\
\hline $\begin{array}{l}\text { Occasionally (once in } 2 \\
\text { months) }\end{array}$ & $0.85(0.56-1.31)$ & $1.18(0.68-2.06)$ \\
\hline Rarely (once in 3 months) & $4.48(2.07-9.72)$ & $3.55(1.55-8.51)$ \\
\hline Never & Ref. & Ref. \\
\hline \multicolumn{3}{|l|}{$\begin{array}{l}\text { ASHA accompanying woman to } \\
\text { her ANC visits }\end{array}$} \\
\hline Regularly (once a month) & $1.02(0.84-1.24)$ & $1.00(0.79-1.27)$ \\
\hline $\begin{array}{l}\text { Occasionally (once in } 2 \\
\text { months) }\end{array}$ & $0.60(0.42-0.85)$ & $0.73(0.45-1.17)$ \\
\hline Rarely (once in 3 months) & $3.13(1.57-6.23)$ & 2.45 (1.17-5.13) \\
\hline Never & Ref. & Ref. \\
\hline \multicolumn{3}{|l|}{$\begin{array}{l}\text { ASHA arranged for ambulance } \\
\text { during labor }\end{array}$} \\
\hline No & $0.59(0.49-0.71)$ & $0.67(0.55-0.82)$ \\
\hline Yes & Ref. & Ref. \\
\hline \multicolumn{3}{|l|}{ Pregnancy outcomes } \\
\hline \multicolumn{3}{|l|}{ Gravida } \\
\hline Primigravida & $0.98(0.81-1.19)$ & $1.02(0.82-1.26)$ \\
\hline Multigravida & Ref. & Ref. \\
\hline \multicolumn{3}{|l|}{ Antenatal checkups } \\
\hline$\leq 4$ antenatal checkups & $2.19(1.13-4.24)$ & $1.91(0.96-3.78)$ \\
\hline 5-9 antenatal checkups & $1.71(0.84-3.50)$ & $1.62(0.77-3.40)$ \\
\hline 10 and more antenatal visits & Ref. & Ref. \\
\hline \multicolumn{3}{|l|}{ Delivery place } \\
\hline Home & $0.43(0.17-1.06)$ & $0.44(0.17-1.13)$ \\
\hline Public institution & $1.22(1.00-1.48)$ & $1.23(1.01-1.51)$ \\
\hline Private institution & Ref. & Ref. \\
\hline
\end{tabular}

The bold/italic highlights the statistically significant values.

*The final model was adjusted for age, pregnant woman's education, partner's education, total monthly household income, microeconomic self-help group, ASHA visits during pregnancy, ASHA accompanying women for ANC visits, ASHA arrangement for ambulance during labor, gravida, birth weight, antenatal checkups, and delivery place.

$\mathrm{AOR}$, adjusted odds ratio; $\mathrm{Cl}$, confidence intervals; $\mathrm{OR}$, odds ratio. 
JSY (AOR: 1.31; 95\% CI: 1.05-1.64) compared with those with more than primary education ( $>8$ years). Women who had a monthly household income of $\leq 4,000$ INR had 1.5 times increased odds of receiving JSY (AOR: 1.47; 95\% CI: 1.04-2.09) compared with women with a monthly household income of $\geq 10,000$.

Women who received rare visits (once in 3 months) from ASHA during pregnancy had $>3.6$ times the odds of receiving JSY benefits compared with those with no visits at all (AOR: 3.55; 95\% CI: 1.55-8.51). However, women who received either regular visits from ASHA during pregnancy or occasional visits compared with no visits were not statistically significant. More specifically in terms of ANC visits, women who were rarely accompanied (once in 3 months) by ASHA during their ANC visits had nearly 2.5 times increased odds of receiving JSY benefits (AOR: 2.45; 95\% CI: $1.17-$ 5.13) compared with those who never had any ASHA visits during ANC. Women who delivered in a subcenter, primary health care center, or district health had 1.2 times increased odds of receiving JSY (AOR: 1.23; 95\% CI: 1.05-1.51) compared with women who delivered at a maternity home/private nursing hospital. However, women who did not receive any planned ambulance transportation service had 0.33 times decreased odds of receiving JSY benefits (AOR: 0.67; 95\% CI: $0.55-0.82$ ) compared to women who received planned ambulance transportation.

\section{Discussion}

Given that JSY implementation occurred in 2005, more than a decade ago, there were vast disparities that continue to exist in receipt of JSY benefits. The present study indicated that only $50 \%$ of marginalized and rural pregnant women benefited from the JSY (conditional cash transfer program), highlighting the inadequacies of the program. Moreover, the receipt of JSY services is much lower than their rural counterparts in other states. ${ }^{12}$ While most of the Indian population (69\%) reside in rural areas, ${ }^{19}$ it is imperative to impart JSY knowledge to women to access and utilize health care to promote healthy and safe births, and reduce maternal and infant mortality. The findings indicate that low-income women, with spousal education being less than primary education, were significant determinants of being a recipient of JSY services. It is worth noting that nearly half $(46.6 \%)$ of those who earned $\leq 4,000$ INR failed to receive JSY benefits highlighting the inherent need that the program did not specifically target the low-income pregnant women for whom the services were intended and favored those within a higher income bracket. More importantly, our findings confirmed that JSY benefits are yet to impact the marginalized women of lower income and educational status, which remains supported by previous studies. ${ }^{4,6,20}$ While JSY has catered to improving institutional delivery and prevent adverse birth outcomes, this analysis shows that among those pregnant women who did not receive JSY, $\sim 10 \%$ reported infant deaths and $14.5 \%$ delivered infants who had low birth weight $(<2,500 \mathrm{~g})$ and $1.9 \%$ had home delivery compared with those who received JSY services.

While it is heartening to report that the majority of the births of JSY beneficiaries occurred in institutional facilities. Similar to other reported studies, our study also showed that delivery in a governmental institution (subcenter, primary health center, or district health center) was significantly associated with the receipt of JSY benefits. ${ }^{7,13,21,22}$ Almost less than half (44.9\%) of the women who received JSY payments delivered within a public facility. However, the majority of women preferred delivery within a maternity home or private nursing. It is crucial to promote institutional delivery since home deliveries can further lead to complications and may lead to severe maternal morbidity or mortality. One possible explanation for preference may have been the quality of obstetric care and services offered in private facilities compared with government facilities, leading to preference for private facilities for their deliveries. ${ }^{23}$ These findings are contrary to the 2015/2016 National Family Health Survey findings in Karnataka, which noted that $\sim 94 \%$ of the births in the previous 5 years occurred in a health facility, of which a majority were in government institutions. ${ }^{15}$

The Government of India also proposed that JSY be facilitated by ASHA workers to provide linkage to health care services during pregnancy. Our study findings showed that JSY receipt of services was not directly connected through ASHA workers, since there was still a majority of those who did not receive JSY benefits, but still had regular or occasional interaction with ASHA workers. In addition, there was limited interaction with health care workers and social workers such as ASHA, specifically among women who did not receive JSY benefits. Similar studies by Dongre and Kapur $^{21}$ and Sidney et al. ${ }^{24}$ indicated that ASHA had limited involvement, with only $28 \%$ being involved during delivery or postdelivery. Although ASHA serves the central role of connecting pregnant women to ANC, identifying institutional delivery site, arranging 
transport, and staying with pregnant women during delivery until time of discharge, the government needs to enact an accountability measure to ensure that the women are indeed well-connected to ASHA to receive JSY services.

There were several inconsistencies with the lack of uniform payment and timely disbursement of the funding with the JSY benefits. Many women (45.5\%) reported having received 1,500 INR, while a small number of women $(1.5 \%)$ had received 500 INR and another $37.7 \%$ reported having received 700 INR. Since Karnataka is assigned as a high-performing state, the government allocates 700 INR to mothers residing in rural areas and 600 INR to mothers residing in urban areas. An underlying reason is that the JSY scheme in Mysore District allocated 700 INR for vaginal delivery and 1,500 INR for cesarean section delivery. However, the remaining women who provided some form, but not all forms, of documentation received 500 INR. According to Doke et al., nearly 20\% of the women faced problems in obtaining BPL certificate of documentation for JSY benefits. ${ }^{25}$

Almost $65 \%$ of the women received the JSY payments after 30 days of delivery. This is contrary to prior studies which noted that the majority of the women received JSY payments within 15 days. It is imperative to understand the inequitable access of payments to the pregnant women. It could be the underlying unpaid work burden that many rural families face. Rural regions in the state of Karnataka have worsened maternal and child health outcomes. ${ }^{15}$ In 2016 alone, rural regions of the state had infant mortality rate of 33 per 1,000 live births compared with the overall infant mortality rate of 28 per 1,000 live births for the state of Karnataka. ${ }^{15}$ This warrants further examination for ensuring that rural regions in highperforming states are still compensated accordingly since they continue to encounter major barriers in access to good-quality obstetric care and services.

This study was among the first to examine the receipt of JSY benefits among rural pregnant women in the South Indian State of Karnataka. The strengths of this study are that it was a prospective cohort study with a large sample size from a rural region within India. In addition, the pregnant women were followed up after birth making it a rich longitudinal data set. Since the questionnaire about JSY was collected in real time and was self-reported, it is more objective. Despite these strengths, there were some limitations. One major limitation of the study was that it did not include a survey question on the ownership of the BPL card as a measure indicator for eligibility of JSY benefits. Therefore, it is difficult to examine if the discrepancies seen are linked to lack of proper documentation, or women with higher as well as lower income levels making them ineligible for JSY benefits.

Furthermore, given that participants were selected from women residing in the Mysore Subdistrict, which is predominantly rural, the findings may not be generalizable to other populations. Due to the self-reporting nature of some questions, it is possible that there may be some degree of information bias. Overall, the study confirmed that allocation of JSY benefits needs to reach the marginalized and vulnerable women in rural Indian states.

\section{Conclusions}

Although the JSY program has been operational since 2005, our study findings show discrepancies in the receipt of JSY scheme in the rural Mysore Subdistrict, India. Therefore, there is an urgent need for targeted education and expansion of comprehensive antenatal services to provide the JSY scheme to rural pregnant women in India and best serve these disproportionately affected women.

\section{Disclaimer}

The content is solely the responsibility of the authors and does not necessarily represent the official views of the National Institutes of Health or the other funding agencies.

\section{Author Disclosure Statement}

The authors declare that they have no conflicts of interest.

\section{Funding Information}

The work was funded by Positive Action for Children Fund. M.S.C. and P.M. were partly supported by the National Institutes of Health NIAID grant R15AI28714-01. P.M. and K.K. were supported by the Global Health Equity Scholars Fellowship funded by the FIC and NHLBI, and NINDS institutes at the National Institutes of Health under Award Number D43 TW010540.

\section{References}

1. World Bank: Maternal mortality ratio (modeled estimate, per 100,000 live births). Available at: https://data.worldbank.org/indicator/SH.STA.MMRT Accessed October 12, 2019.

2. Goli S, Jaleel AC. What is the cause of the decline in maternal mortality in India? Evidence from time series and cross-sectional analyses. J Biosoc Sci 2014;46:351-365. 
3. Sidney K, Salazar M, Marrone G, Diwan V, DeCosta A, Lindholm L. Out-ofpocket expenditures for childbirth in the context of the Janani Suraksha Yojana (JSY) cash transfer program to promote facility births: Who pays and how much? Studies from Madhya Pradesh, India. Int J Equity Health 2016;15:71.

4. Sengupta NaAaS. Is India's safe motherhood scheme leading to better child health care practices? Glob Soc Welf 2018;5:49-58.

5. Mukherjee S, Singh A. Has the Janani Suraksha Yojana (a conditional maternity benefit transfer scheme) succeeded in reducing the economic burden of maternity in rural India? Evidence from the Varanasi district of Uttar Pradesh. J Public Health Res 2018;7:957.

6. Lim SS, Dandona L, Hoisington JA, James SL, Hogan MC, Gakidou E. India's Janani Suraksha Yojana, a conditional cash transfer programme to increase births in health facilities: An impact evaluation. Lancet 2010;375: 2009-2023.

7. Gupta SK, Pal DK, Tiwari R, et al. Impact of Janani Suraksha Yojana on institutional delivery rate and maternal morbidity and mortality: An observational study in India. J Health Popul Nutr 2012;30:464-471.

8. Vora KS, Koblinsky SA, Koblinsky MA. Predictors of maternal health services utilization by poor, rural women: A comparative study in Indian States of Gujarat and Tamil Nadu. J Health Popul Nutr 2015;33:9.

9. Government of India, Minsitry of Health and Family Welfare. Janani Suraksha Yojana features and frequently asked questions and answers. 2005. Available at: https://mohfw.gov.in/sites/default/files/FEATURES\% 20FREQUENTLY\%20ASKED\%20QUESTIONS.pdf Accessed October 12, 2019.

10. Powell-Jackson T, Pereira SK, Dutt V, Tougher S, Haldar K, Kumar P. Cash transfers, maternal depression and emotional well-being: Quasiexperimental evidence from India's Janani Suraksha Yojana programme. Soc Sci Med 2016;162:210-218.

11. Rahman MM, Pallikadavath S. How much do conditional cash transfers increase the utilization of maternal and child health care services? New evidence from Janani Suraksha Yojana in India. Econ Hum Biol 2018;31:164-183.

12. Singh VS, Chavan SS, Giri PA, Suryavanshi SR. Study on awareness and knowledge regarding Janani Suraksha Yojana (JSY) among ANC registered women in a primary health centre of tribal area of Thane District of Maharashtra. Int J Res Med Sci 2014;2:122-126.

13. Thongkong N, van de Poel E, Roy SS, Rath S, Houweling TA. How equitable is the uptake of conditional cash transfers for maternity care in India? Evidence from the Janani Suraksha Yojana scheme in Odisha and Jharkhand. Int J Equity Health 2017;16:48.

14. Mysore District: Census 2011 data. Published Census 2011. Available at: https://www.census2011.co.in/census/district/263-mysore.html Accessed October 12, 2019.

15. National Family Health Survey (NFHS-4). International Institute for Population Sciences, 2016. Available at: http://rchiips.org/nfhs/karnatak.shtml Accessed October 12, 2019

16. Kojima N, Krupp K, Ravi K, et al. Implementing and sustaining a mobile medical clinic for prenatal care and sexually transmitted infection prevention in rural Mysore, India. BMC Infect Dis 2017;17:189.

17. National Statistics Office Ministry of Statistics and Programme Implementation of India. Press note on the First Advance Estimates of National Income 2018-19. Available at: www.mospi.gov.in/sites/default/files/ press release/Presss\%20note\%20for\%20first\%20advance\% 20estimates\%202018-19.pdf Accessed October 12, 2019.

18. Chaturvedi S, De Costa A, Raven J. Does the Janani Suraksha Yojana cash transfer programme to promote facility births in India ensure skilled birth attendance? A qualitative study of intrapartum care in Madhya Pradesh. Glob Health Action 2015;8:27427.

19. Budhwani $H$, Shivkumar $P$, Purandare $C N$, et al. Examining the use of magnesium sulfate to treat pregnant women with preeclampsia and eclampsia: Results of a program assessment of emergency obstetric care (EmOC) training in India. J Obstetr Gynecol India 2017;67:330-336.

20. Vikram K, Sharma AK, Kannan AT. Beneficiary level factors influencing Janani Suraksha Yojana utilization in urban slum population of transYamuna area of Delhi. Indian J Med Res 2013;138:340-346.

21. Dongre A, Kapur A. How is Janani Suraksha Yojana performing in backward districts of India? Econ Pol Weekly 2013;43:53-59.

22. Panja TK, Mukhopadhyay DK, Sinha N, Saren AB, Sinhababu A, Biswas $A B$. Are institutional deliveries promoted by Janani Suraksha Yojana in a district of West Bengal, India? Indian J Public Health 2012; 56:69-72.
23. Bruce SG, Blanchard AK, Gurav K, et al. Preferences for infant delivery site among pregnant women and new mothers in Northern Karnataka, India. BMC Pregn Childbirth 2015;15:49.

24. Sidney K, Diwan V, El-Khatib Z, De Costa A. India's JSY cash transfer program for maternal health: Who participates and who doesn't-a report from Ujjain district. Reprod Health 2012;9:2.

25. Doke P, Gawande U, Deshpande S, Gadgil M. Evaluation of Janani Suraksha Yojana (JSY) in Maharashtra, India: Important lessons for implementation. Int J Trop Dis Heal 2015;5:141-155.

Cite this article as: Kiplagat $S$, Coudray MS, Ravi K, Jayakrishna $P$, Krupp K, Arun A, Madhivanan P (2020) Evaluating a conditional cash transfer scheme in a maternal health care utilization program among rural pregnant women in Mysore District, India, Women's Health Report 1:1, 159-166, DOI: 10.1089/whr.2019.0021

$\begin{aligned} & \text { Abbreviations Used } \\ & \mathrm{ANC}= \text { antenatal care } \\ & \mathrm{ANM}=\text { auxiliary nurse midwives } \\ & \mathrm{AOR}=\text { adjusted odds ratio } \\ & \mathrm{ASHA}=\text { Accredited Social Health Activists } \\ & \mathrm{BPL}=\text { below poverty line } \\ & \mathrm{Cl}=\text { confidence interval } \\ & \mathrm{INR}=\text { Indian Rupees } \\ & \mathrm{JSY}=\text { Janani Suraksha Yojana } \\ & \mathrm{MMR}=\text { maternal mortality ratio } \\ & \mathrm{OR}=\text { odds ratio } \\ & \mathrm{SCIL}=\text { Saving Children Improving Lives } \\ & \mathrm{SD}=\text { standard deviation } \\ & \mathrm{USD}=\text { U.S. Dollar }\end{aligned}$

